\title{
Motivação para ensinar e aprender em tempo de pandemia
}

\author{
Motivation to teach and learn in time of a pandemic \\ Motivación para enseñar y aprender en tiempos de pandemia
}

Recebido: 30/11/2021 | Revisado: 04/12/2021 | Aceito: 10/12/2021 | Publicado: 18/12/2021

\author{
Hérika Cristina Oliveira da Costa \\ ORCID: https://orcid.org/0000-0002-6531-3054 \\ Universidad Columbia del Paraguay, Paraguai \\ E-mail: h_co_c@ @otmail.com \\ Aline dos Santos Moreira de Carvalho \\ ORCID: https://orcid.org/0000-0001-9965-9566 \\ Universidad Columbia del Paraguay, Paraguai \\ E-mail: bioaline2017@yahoo.com \\ Thatiana Soares dos Santos \\ ORCID: https://orcid.org0000-0001-5217-3462 \\ Universidad Columbia del Paraguay, Paraguai \\ E-mail: thatianasoaresdossantos@gmail.com \\ Pedro Carlos Pereira \\ ORCID: https://orcid.org/0000-0003-4646-0080 \\ Universidade Federal Rural do Rio de Janeiro, Brasil \\ Universidad Columbia del Paraguay, Paraguai \\ E-mail: pecape@ig.com.br
}

\begin{abstract}
Resumo
O artigo tem como objetivo identificar as percepções sobre a motivação dos alunos no período de pandemia da COVID-19. A motivação envolve fatores biológicos, emocionais e sociais. Pode-se dizer que é um impulso que faz com que as pessoas passam a correr atrás de seus objetivos sendo muito importante no cumprimento de suas tarefas. Sem motivação o ser humano se sente apático a realizar e alcançar seus objetivos pessoais e/ou profissionais. Ela pode ocorrer através de uma energia, força interior, que pode ser chamada como motivação intrínseca ou automotivação. Com o período de pandemia, devido à suspensão das aulas presenciais e a limitação dos recursos, aplicamos a seguinte pesquisa qualitativa com alguns alunos da rede pública do Estado do Rio de Janeiro, especificamente da cidade de Carapebus. O que é Motivação? Sentem-se motivados a estudar em tempo de Pandemia, justifique a sua resposta? Quais as maiores dificuldades encontradas? Sugestões de atividades que gostariam de realizar nesse período?
\end{abstract}

Palavras-chave: Motivação; Pandemia; Aprendizagem.

\begin{abstract}
The article aims to identify the perceptions of student motivation during the COVID-19 pandemic period. Motivation involves biological, emotional and social factors. It can be said that it is an impulse that makes people chase their goals, being very important in fulfilling their tasks. Without motivation, human beings feel apathetic to accomplishing and achieving their personal and/or professional goals. It can occur through an energy, inner force, which can be called intrinsic motivation or self-motivation. With the pandemic period, due to the suspension of classroom classes and limited resources, we applied the following qualitative research with some public school students in the State of Rio de Janeiro, specifically in the city of Carapebus. What is Motivation? Are you motivated to study in time of Pandemic, justify your answer? What are the biggest difficulties encountered? Suggestions of activities you would like to do during this period?
\end{abstract}

Keywords: Motivation; Pandemic; Learning.

\section{Resumen}

El artículo tiene como objetivo identificar las percepciones de la motivación de los estudiantes durante el período de la pandemia COVID-19. La motivación involucra factores biológicos, emocionales y sociales. Se puede decir que es un impulso que hace que las personas persigan sus metas, siendo muy importante en el cumplimiento de sus tareas. Sin motivación, los seres humanos se sienten apáticos para lograr y alcanzar sus metas personales y / o profesionales. Puede ocurrir a través de una energía, fuerza interior, que se puede llamar motivación intrínseca o automotivación. Con el período de la pandemia, debido a la suspensión de las clases presenciales y los recursos limitados, aplicamos la siguiente investigación cualitativa con algunos estudiantes de escuelas públicas en el estado de Río de Janeiro, específicamente en la ciudad de Carapebus. ¿Qué es la motivación? ¿Estás motivado para estudiar en tiempos de 
Pandemia, justifica tu respuesta? ¿Cuáles son las mayores dificultades encontradas? ¿Sugerencias de actividades que le gustaría realizar durante este período?

Palabras clave: Motivación; Pandemia; Aprendiendo.

\section{Introdução}

A temática motivação docente tem ocupado lugar de destaque nos debates em educação no seu papel de mobilização do estudante para a aprendizagem duradoura, como enfatiza Pozo (2002). A pandemia do COVID-19, fez com que muito se repensasse sobre a melhor forma de ensinar, levando em consideração os alunos que perderam o interesse pelos estudos. No cenário internacional, a temática tem relevância, com enfoque na formação de professores, como afirma Bunzeck (2009), por sugerir importantes e significativas mudanças nas práticas pedagógicas da Educação Básica.

Segundo Torre (1999), "a motivação escolar é algo complexo, processual e contextual, mas alguma coisa se pode fazer para que os alunos recuperem ou mantenham seu interesse em aprender" (p. 09). Sabe-se que é uma tarefa árdua o professor se manter $100 \%$ motivado devido a inúmeros fatores, porém é necessário para todos sejam beneficiados. Faz-se necessário identificar como despertar interesse quanto ao aprendizado. A prática docente tem demonstrado que professores motivados promovem uma ação docente dinâmica e criativa através do emprego de metodologias que vão ao encontro dos interesses e necessidades dos estudantes, despertando-lhes a atenção em sala de aula.

Ademais, apresentamos brevemente estudos que versam sobre a motivação e o desafio dos docentes, em tempo de pandemia, na identificação de estratégias para desenvolverem com seus alunos de forma dinâmica, estimulando as múltiplas inteligências e tornando o ambiente prazeroso e motivador.

\section{Metodologia}

A metodologia utilizada para a produção deste estudo foi de pesquisa bibliográfica, realizada em meio virtual, com artigo disponível e e-books em sites confiáveis, de conteúdo científico e a aplicação de questionário, com perguntas fechadas, aos alunos.

A pesquisa bibliográfica, ou de fontes secundárias, abrange toda bibliografia já tornada pública em relação ao tema de estudo, desde publicações avulsas, boletins, jornais, revistas, livros, pesquisas, monografias, teses, material cartográfico etc. [...] Dessa forma, a pesquisa bibliográfica não é mera repetição do que já foi dito ou escrito sobre certo assunto, mas propicia o exame de um tema sob novo enfoque ou abordagem, chegando a conclusões inovadoras (Lakatos \& Marconi, 2010, p.166).

Artigos que não correlacionavam os quatro descritores foram excluídos. Após a exclusão, foi feita uma leitura analítica que resultou na fundamentação teórica deste estudo, apresentada em resultados e discussões e subdividida em títulos.

As conclusões, incluindo algumas propostas e as impressões dos autores, encontram-se nas considerações finais.

Assim, e tomando por base as definições de Vergara (1995), que define quanto aos fins; exploratória, esta investigação foi realizada tendo como desafio maior a identificação e a percepção dos alunos da referida turma, nessa realidade onde se utilizou a metodologia de ensino remota.

\section{Resultados e Discussão}

No dicionário Aurélio a definição da palavra motivação é a seguinte: Ato ou efeito de motivar; exposição de motivos ou causas; conjunto de fatores que determinam a atividade e a conduta individuais.

A motivação envolve fatores biológicos, emocionais e sociais. Pode-se dizer que é um impulso que faz com que as pessoas passam a correr atrás de seus objetivos sendo muito importante no cumprimento de suas tarefas. Sem motivação o ser 
humano se sente apático a realizar e alcançar seus objetivos pessoais e/ou profissionais. Ela pode ocorrer através de uma energia, força interior, que pode ser chamada como motivação intrínseca ou automotivação.

Maslow e McClelland em diversos estudos criam suas teorias para a Motivação. Maslow afirma que o ser humano se motiva quando suas necessidades são alcançadas, como a auto realização, autoestima, necessidades sociais, necessidades fisiológicas e segurança. McClelland cita três necessidades que são essenciais para a motivação: poder, afiliação e realização.

Outro estudioso do tema é Daniel Pink em seu livro Motivação 3.0, fala da Motivação intrínseca relacionada ao comportamento humano. Ele cita três pilares para despertar essa motivação e mantê-la, são: Autonomia, Excelência e o Propósito.

Desta forma com base nos estudos e leitura feitos de acervos digitais, periódicos, revistas cientificas e diversos artigos, obras literárias, além do momento que ainda estamos vivenciando com a COVID-19, realizamos a pesquisa em questão.

Com o período de pandemia, devido à suspensão das aulas presenciais e a limitação dos recursos, aplicamos a seguinte pesquisa qualitativa com alguns alunos da rede pública do Estado do Rio de Janeiro, especificamente da cidade de Carapebus. O que é Motivação? Sentem-se motivados a estudar em tempo de Pandemia, justifique a sua resposta? Quais as maiores dificuldades encontradas? Sugestões de atividades que gostariam de realizar nesse período?

Quadro 1. Sobre a primeira pergunta: $O$ que é Motivação?

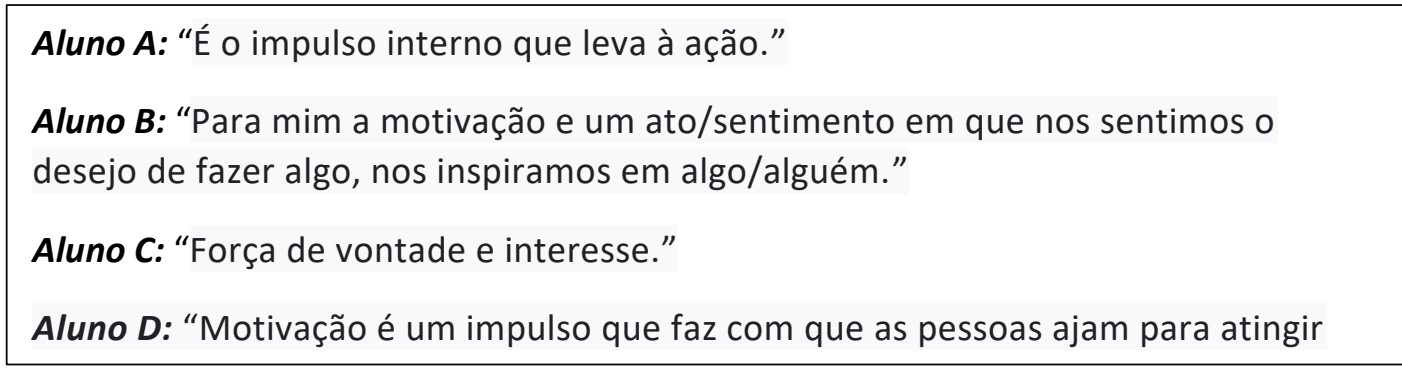

Fonte: Autores.

Percebemos nas falas, todos entendem e conseguem descrever em poucas palavras o que é motivação. Acredita-se que está atrelado aos seus objetivos, algo profundo.

Gráfico 1. Segunda pergunta: Sentem-se motivados a estudar em tempo de Pandemia? Justifique a sua resposta.

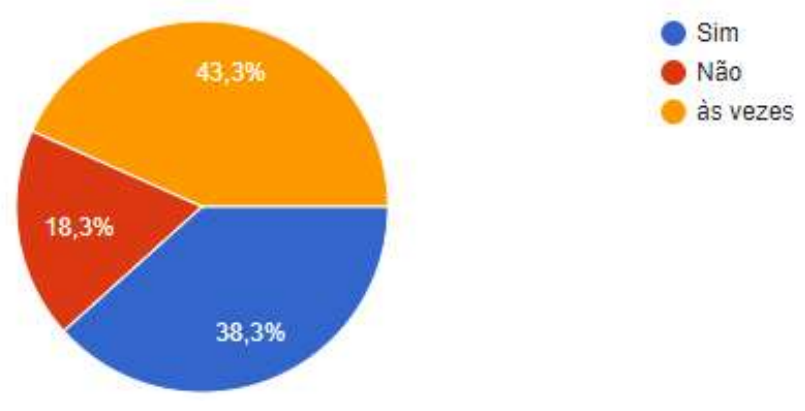

Fonte: Autores. 


\section{Quadro 2.}

Aluno A: "Às vezes, porque nem todo dia me sinto motivada para fazer as atividades, mais mesmo assim faço."

Aluno B: "Porque tem dias que eu acordo querendo estudar e tem dias que não, mas mesmo assim eu estudo."

Aluno C: "Me sinto frustrada por não conseguir acompanhar as aulas por falta de ferramentas."

Aluno D: "Por sentir falta das explicações presenciais, isso faz com que às vezes não tenhamos motivação para estudar."

Fonte: Autores.

No gráfico acima tivemos um percentual de $43,3 \%$ de alunos que responderam talvez, como percebemos uma grande parte oscilou na expectativa dos estudos durante a pandemia.

Quadro 3. Terceira pergunta: Quais as maiores dificuldades encontradas?

Aluno A: "Muitas vezes porque eu tenho que aprender a matéria sozinha e sem ajuda, ficar em casa também não ajuda."

Aluno B: "Falta de recursos."

Aluno C: "A falta de um dispositivo para estudar, pois os nossos dispositivos não têm capacidade para instalar aplicativos"

Aluno D: "Por dificuldades como: a falta de formação, o despreparo, à falta de recursos"

Fonte: Autores.

Percebemos que neste questionamento a maior parte dos alunos que apresenta dificuldade afirma que a falta de recursos, contribui para sua desmotivação para a aprendizagem.

Quadro 4. Quarta pergunta: Sugestões de atividades que gostariam de realizar nesse período?

Aluno A: "Atividades com jogos."

Aluno B: "Atividade mais dinâmica."

Aluno C: "Um dever mais educativo e mais divertido que todos possam fazer juntos."

Aluno D: "Algumas atividades mais dinâmicas." 
Nesta última pergunta, os alunos deram algumas sugestões para que as atividades trouxessem uma motivação, um gás para os estudos, já que os mesmos estavam somente com material impresso e tendo aulas via WhatsApp. Em que os professores somente postavam as atividades nos grupos das turmas.

Diante de toda essa pesquisa, citaremos os estudos de Daniel Pink, Maslow, McClelland sobre a motivação e como podemos associá-la como um aspecto importante para a prática docente e a mudança de comportamento.

Segundo a Teoria da Motivação de Maslow, o ser humano tem algumas necessidades, que são elas: Fisiológicas, segurança, afiliação, estima (reconhecimento) e autor realização.

- As fisiológicas, são as necessidades típicas para a nossa sobrevivência: comer, respirar, beber etc.

- As de segurança, são aquelas em que nos fazem sentir protegidos.

- As de afiliação, estão associadas com o social. O ser humano sente e precisa da interação, caso contrário se sente sozinha e isolada da sociedade.

- As necessidades de reconhecimento, são aquelas no qual as pessoas se sentem satisfeitas.

- As de autor realização são aquelas em uma pessoa se considera bem-sucedida, confiante de si mesmo.

Já na teoria de David McClelland chamada de Teoria da motivação pelo êxito e/ou medo, para ele as principais necessidades para que um ser humano pudesse obter a satisfação eram: Realização, afiliação e poder, ele afirma na sua teoria que cada pessoa tem uma necessidade diferente uma da outra.

A necessidade de realização revela que pessoas que atingem o nível alto desta necessidade buscam excelência. Na segunda necessidade, tão quanto baseada na Teoria de Maslow, existe também a de afiliação em que as pessoas nesta categoria necessitam ter relações harmoniosas com outras pessoas, para que não se sintam excluídas do grupo social. E a última é a de poder, no qual essa necessidade pode ser dividida em dois tipos: pessoal (poder de comandar os demais) e institucional.

Daniel Pink (2019), cita três pilares para despertar a motivação intrínseca e mantê-la. É a Autonomia, Excelência e Propósito.

No primeiro pilar que é a autonomia, Daniel afirma que precisamos incentivar os seres humanos a ter autonomia, para que se tenha a motivação em querer aprender ou de algo que gostaria de fazer.

No pilar sobre excelência ele afirma que é o estágio em que o ser humano ao escolher uma atividade e ao realizá-la se percebe cada vez melhor. Esse pilar está associado à Teoria de Flow do psicólogo Húngaro Mihaly Csikszentmihaly.

No terceiro e último pilar que é o propósito, está relacionado à vontade de ver aquilo que estamos realizando e que cada dia se torne maior. É o que nos dá o ânimo para viver.

Portanto quando temos esses três pilares, conseguimos direcionar nossas ações para a motivação intrínseca.

Diante dessa pesquisa revalidamos através das teorias mencionadas que existe a necessidade de que seja despertada no professor e no aluno essa motivação, esses pilares. Há uma necessidade de mobilização de saberes, por parte dos professores, para está engajando os seus alunos no processo de ensino e aprendizagem. Assim, como os alunos precisam ter consciência dos seus objetivos e metas, pois se acredita que a motivação se manifesta no processo de ensino e a aprendizagem quando existem interesse, envolvimento, esforço, concentração e satisfação dos alunos.

Segundo Kauark e Muniz (2011):

"Os professores-educadores devem ser estudantes vitalícios, engajados não apenas no mero estudo, mas também mergulhados na prática. Somente a chama de uma lamparina acesa pode ascender outras chamas." 
O novo desafio dos docentes da sociedade atual e do conhecimento é ser criativo, preparar aulas dinâmicas e engajar seus alunos na prática docente, seja ela dentro ou fora da sala de aula, desta forma, precisa-se estimular as múltiplas inteligências, para da possibilidade de gerar criatividade e que o ambiente se torne prazeroso e motivador.

Porém segundo Scwartz apud Morin (1998,1999, 2000) Motivação é um tema complexo assim como são as articulações desse fenômeno com os processos de ensino e de aprendizagem.

\section{Conclusões Finais}

Quando estudamos o ser humano e suas questões emocionais, nos deparamos constantemente com a necessidade de acolhimento, motivação, dinamismo e estímulo para que o trabalho ou aprendizado seja realizado e consolidado.

Com a pandemia da Covid-19 a falta de motivação foi evidente. Alunos desmotivados, professores estressados, apresentando aulas engessadas e sem entusiasmo.

A evasão escolar foi um fato que chamou atenção durante a pandemia, seja por falta de recursos tecnológicos ou pelo não aprendizado dos alunos que simplesmente copiavam o que era reproduzido pelo professor.

Precisamos incentivar os seres humanos a ter autonomia, para que tenha a motivação em querer aprender ou de algo que gostaria de fazer. Faz-se necessário que seja despertada no professor e no aluno essa motivação, esses pilares. Há uma necessidade de mobilização de saberes, por parte dos professores, para está engajando os seus alunos no processo de ensino e aprendizagem. Assim, como os alunos precisam ter consciência dos seus objetivos e metas, pois se acredita que a motivação se manifesta no processo de ensino e a aprendizagem quando existem interesse, envolvimento, esforço, concentração e satisfação dos alunos.

Diante do apresentado precisamos de mudanças nas políticas públicas, mudanças essas que estimulem o professor, oferecendo cursos e atualizações, valorizando os profissionais criativos. Com isso acreditamos que as aulas terão um novo formato, a partir do uso de metodologias ativas os alunos serão estimulados, com isso acreditamos num maior engajamento e automaticamente na melhora do rendimento escolar.

\section{Referências}

Boher, R. S. (1981). Motivação: abordagem critica da teoria de Maslow pela propaganda. Revista de Administração de Empresas, 21 (4), $43-47$.

Boruchovitch, E., \& Bzuneck, J. A. (2011) A motivação do aluno: contribuições da psicologia contemporânea. (4a ed.), Vozes.

Carvalho, D. C. de. (2001). A psicologia frente à educação e o trabalho docente. Psicologia em Estudo, 7(1), 51-60.

Eccheli, S. D. (2008). A motivação como prevenção da indisciplina. Educar, (32), 199-213.

Guimaraes, S. É. R., \& Boruchovitch, E. (2004). O estilo motivacional do professor e a motivação intrínseca dos estudantes: uma perspectiva da Teoria da Autodeterminação. Psicologia: Reflexão e Crítica, 17(2), 143-150.

J. A. Bzuneck. (2009). A motivação do aluno: Aspectos introdutórios. In: Boruchovitch, Evely, Bzunek, José Aloyseo. A motivação do aluno: contribuições da psicologia contemporânea. Vozes, 9-36.

Jesus, S. N. de, \& Santos, J. C. V. (2004). Desenvolvimento profissional e motivação dos professores. Educação: Revista da Faculdade de Educação, PUCRS, $27(52), 39-58$.

J. I. Pozo. (2002). Aprendizes e Mestres: a nova cultura da aprendizagem. Artmed Editora.

Kauark, F., \& Muniz, L. Motivação no ensino e na aprendizagem: competências e criatividade na prática pedagógica. (2a ed.), WakEd.

Leonardo, Jefferson Marco Antônio. (2002). A guerra do sucesso pelos talentos humanos. Production, 12(2), $42-53$.

Machado, A. C. T. A., et al. (2012). Estilos motivacionais de professores: preferência por controle ou por autonomia, Psicologia: Ciência e Profissão, 32(1), $188-201$.

Marchelli, P. S., Dias, C. L., \& Schimidt. (2008). Autonomia e mudança na escola: novos rumos dos processos de ensino- aprendizagem do Brasil. Revista Psicopedagogia, 25(78), 271-81. 
Research, Society and Development, v. 10, n. 16, e558101624122, 2021 (CC BY 4.0) | ISSN 2525-3409 | DOI: http://dx.doi.org/10.33448/rsd-v10i16.24122

Mognon, J. F. (2010). Motivação para aprender na escola. Psico-USF. 15(2), 273-275.

Monteiro, M. A. A. et al. (2012). A influência do discurso do professor na motivação e na interação social em sala de aula. Ciência \& Educação. 18(4), 9971010 .

Oliveira, C. B. E. de, \& Alves, P. B. (2005). Ensino fundamental: papel do professor, motivação e estimulação no contexto escolar. Paidéia. 15(31), 227-238.

Otaviano, A. B. N., Alencar, E. M. L. S. de, Fukuda, C. C. (2012). Estímulo à criatividade por professores de Matemática e motivação do aluno. Psicologia Escolar e Educacional, 16(1), 61-69.

Pasqualini, Juliana Campregher. (2009). A perspectiva histórico-dialética da periodização do desenvolvimento infantil. Psicologia em Estudo, 14(1), 31-40.

Pink, D. (2019). Motivação 3.0. Sextante.

Schwartz, S. (2014). Motivação para ensinar e aprender: teoria e prática. Vozes.

Teoria motivacional de Maslow - Resumo e Exemplos (psicologia-online.com)

Tapia, J. A. (1999). Contexto, motivação e aprendizagem. In: Tapia, J. A., Fita, E. C. A motivação em sala de aula: o que é, como se faz. (4a ed.), Loyola, 1161. 